\title{
Characteristics of aeromedical transport, both interhospital and directly from the scene of the incident, in patients with acute myocardial infarction or acute trauma between 2011-2016 in Poland: A case-control study
}

\author{
Arkadiusz Wejnarski ${ }^{1, A-F}$, Piotr Leszczyński, ${ }^{1, E}$, Stanisław Świeżewski ${ }^{2, C}$, Marcin Podgórski ${ }^{2, B}$, Michał M. Farkowski ${ }^{3, \mathrm{E}}$, \\ Maciej Sterliński ${ }^{4, E}$, Mariusz Panczyk ${ }^{5, C}$, Joanna Gotlib ${ }^{5, C}$, Daniel Rabczenko ${ }^{6, B}$, Robert Gałązkowski2, ${ }^{2}$ \\ ${ }^{1}$ Institute of Health Sciences, Faculty of Medical and Health Sciences, Siedlce University of Natural Sciences and Humanities, Poland \\ ${ }^{2}$ Department of Emergency Medical Services, Faculty of Health Science, Medical University of Warsaw, Poland \\ ${ }^{3}$ Heart Arrhythmia Ward, II Department of Coronary Artery Disease, Institute of Cardiology, Warszawa, Poland \\ ${ }^{4}$ Clinic of Cardiac Arrhythmias, Institute of Cardiology, Warszawa, Poland \\ ${ }^{5}$ Department of Education and Research in Health Sciences, Faculty of Health Sciences, Medical University of Warsaw, Poland \\ ${ }^{6}$ National Institute of Public Health - National Institute of Hygiene, Warszawa, Poland \\ A - research concept and design; B - collection and/or assembly of data; $C$ - data analysis and interpretation; \\ $D$ - writing the article; $E$ - critical revision of the article; $F$ - final approval of the article
}

\section{Address for correspondence \\ Arkadiusz Wejnarski}

E-mail: a.wejnarski@gmail.com

Funding sources

None declared

Conflict of interest

None declared

Received on October 29, 2018

Reviewed on April 27, 2019

Accepted on May 17, 2019

Published online on November 28, 2019

Cite as

Wejnarski A, Leszzzyński P, Świeżewski S, et al. Characteristics of aeromedical transport, both inter-hospital and directly from the scene of the incident, in patients with acute myocardial infarction or acute trauma between 2011-2016 in Poland: A case-control study. Adv Clin Exp Med. 2019;28(11):1495-1505. doi:10.17219/acem/109456

DOI

10.17219/acem/109456

Copyright

Copyright by Author(s)

This is an article distributed under the terms of the Creative Commons Attribution 3.0 Unported (CC BY 3.0) (https://creativecommons.org/licenses/by/3.0/)

\begin{abstract}
Background. Patients with acute myocardial infarction (AMI) or acute trauma (AT) are transported by air to save time. Helicopter Emergency Medical Service (HEMS) provides both flights to and from the emergency scene, as well as interhospital transport (interHtransport).
\end{abstract}

Objectives. The objective of this study was to compare aeromedical transport and HEMS missions of AMI and AT patients regarding safety, medical procedures and the length of flights.

Material and methods. This is a case-control study analyzing the medical history records of AMI and AT patients transported between hospitals and from the scene identified using ICD-10 codes. Research of customary data (age, sex and general health status measured with Glasgow Coma Scale (GCS) and Revised Trauma Score (RTS)) was performed.

Results. There were 48,555 flights in the years 2011-2016, of which 7,645 (15.7\%) were interhospital (19\% AMl and 12\% AT). Out of these, 40,910 (84.3\%) HEMS missions were to patients on the scene (10\% AMl and 13\% AT). No fatalities were noted. The AMI GCS score was higher than in AT patients: 15.0 vs 14.0, respectively. The medical procedures during transport of AMl patients between hospitals and from the scene were the following: cardiopulmonary resuscitation (CPR): 6 vs 73 cases ( $p<0.001)$; oxygen therapy: $41.1 \%$ vs $50.2 \%$, respectively. The median distance was $59.4 \mathrm{~km}$ vs $52.1 \mathrm{~km}(\mathrm{p}<0.001)$, while median flight time was 45.0 min vs $38.0 \mathrm{~min}(p<0.001)$, respectively. Regarding AT patients, the procedures performed (during interhospital and from the scene transport) were the following: (PR: 5 vs 244 cases $(p<0.001)$; intubation: $10.7 \%$ vs $17.3 \%$ ( $p<0.001$ ); sedation: $50.1 \%$ vs $24.3 \%$ ( $p<0.001$ ); oxygen therapy: $17.6 \%$ vs $36.6 \%$ ( $p<0.001$ ); spinal board: $17.1 \%$ vs $66 \%$ ( $p<0.001$ ); cervical collar: $15.9 \%$ vs $63.4 \%$ ( $<<0.001$ ), respectively. Interhospital transport and HEMS mission median flight distance was $135.9 \mathrm{~km}$ vs $56.3 \mathrm{~km}$ $(p<0.001)$, while median flight time was 66.0 min vs $45.0 \mathrm{~min}(p<0.001)$, respectively.

Conclusions. Aeromedical transport is safe and very rarely requires resuscitation during the flight. The long distances of flights and time required can reflect the scarcity of trauma centers (TCS) compared to cardiovascular wards. The location of hemodynamic centers in Poland is optimal.

Key words: acute myocardial infarction, Helicopter Emergency Medical Service, aeromedical transport, patient with trauma 


\section{Introduction}

Similarly to the rest of the world, in Poland aeromedical interhospital transport (interHtransport) in the rescue mode is the most frequent form of transporting both patients with acute trauma (AT) and with acute myocardial infarction (AMI) ${ }^{1,2}$ The Medical Air Rescue Service (MARS) has at its disposal 2 kinds of aircraft: 22 EC $1352+$ and H135 P3 helicopters, forming the Helicopter Emergency Medical Service (HEMS). Of all its air bases, 4 work all year while 1 is seasonal and operates only in the summer. The other kinds of aircraft are 2 Plane Transport Teams (PTS), which mostly provide interHtransport of patients in the planned mode. In addition to carrying out flights to the immediate scene of the emergency incident, HEMS is also used for rescue transport between treatment institutions which have helipads (functioning either during the day or round-the-clock). It is essential to transport the AMI patient in a sudden critical health condition who requires intensive supervision during the flight to a hospital which has a hemodynamics department, so that percutaneous coronary intervention (PCI) can be carried out. ${ }^{1,3}$ The responsibility for the organization and choice of transport mode between an ambulance and a helicopter falls on the dispatching doctor who is in charge of the patient. The decision can be consulted with the doctor from the interventional cardiology department. The procedures described above function both in the Polish and in the American healthcare system. ${ }^{4,5}$ In the case of patients in a critical condition, when making the decision about transport to another center, the doctor in charge of the patient must first make sure that all the diagnostic and treatment possibilities have been exhausted and then must be guided by the principle that potential benefits should outweigh risks, including that of death in the course of transport. ${ }^{6}$

Transport takes place between hospitals that have adjacent helipads. In each and every case enrollment of the patients for transport is implemented by the medical dispatcher of the Operational Center of the Medical Air Rescue Service (OP MARS), who then actively participates in coordinating transport operations. Research reports from all the world all agree that when it comes to saving time, aeromedical transport of AMI patients from the place of the incident to the center implementing PCI is superior to transport from hospital to hospital. ${ }^{4}$ In fact, under Polish conditions, where many hospitals have no land transport units, HEMS is the only possibility of transporting a patient in a critical, life-threatening condition.

Under the law, every medical legal entity in Poland is obliged to provide sanitary transport to a patient in a critical condition to the nearest appropriate medical facility. Such a policy is based on the premise that immediate treatment or continuation of treatment must be provided. In practice, transport contracts made between medical units and an enterprise carrying out sanitary transport (often located at a distance of a few dozen kilometers from the dispatching hospital) are also accepted. In such cases, air transport is the desirable alternative to land transport. The key factor is to make sure that aircraft are dispatched in an optimal way, so that more patients can be helped.

Flights to AT patients who have suffered injuries in road or construction accident and other events resulting in lifethreatening situations are as frequent as cases of AMI. Patients fulfilling the criteria for enrollment in a trauma center (TC), a center for the treatment of burns or a hospital performing the replantation of limbs can be transported by air, which is beneficial from the point of view of saving time, minimizes the shaking present during ambulance transport ${ }^{7,8}$ and also reduces the fatality rate. ${ }^{9,10}$ When comparing land and aeromedical transport in the course of implementing vital procedures, an important role is played by the exceptional professional experience of HEMS teams. ${ }^{11}$

In Poland there are 14 TCs for 16 voivodeships (provinces). In this context, ambulance transport over a distance of many kilometers can lengthen the time of reaching the patients and transporting them to a place where specialist treatment can be provided. In most cases, reports regarding the air transport of AMI patients do not distinguish cases of cardiac arrest or fatality. What is featured in reports are cases of hypotension in the course of the flight. ${ }^{2,12}$

The aim of the present study was to compare the transport of AMI and AT patients carried out by HEMS regarding undertaken medical procedures as well as the time and distance of flights.

\section{Material and methods}

A case-control study was performed using the medical and air histories of MARS regarding patients transported in the course of interhospital operations and flights to the immediate scene of the emergency incident (HEMS missions) in the years 2011-2016 in Poland. Both the medical and flight data were recorded using Microsoft Excel (Microsoft Inc., Redmond, USA) databases.

The group that was researched were patients transported due to acute coronary syndrome, identified by the following ICD-10 codes: I20, I21 and I24. The control group comprised AT patients identified by the following ICD-10 codes: S06, T06, T29, and S68. They were the second most numerous homogeneous group of patients transported during HEMS rescue service flights.

The data that was identified and compared concerned: 1) age, sex, patient status (on the basis of Glasgow Coma Scale (GCS) and Revised Trauma Score (RTS)) and death in the course of flight; 2) the medical procedures undertaken (external heart massage, defibrillation, sedation, neuromuscular block, oxygen therapy, respiratory 
therapy, intubation, or using a spinal board, a cervical collar or a painkiller; 3 ) the time and distance of the flight.

\section{Statistical analysis}

Descriptive statistics are presented as the numerical data and percentages of categorical variables and the median weighted with the $1^{\text {st }}$ and $3^{\text {rd }}$ quartile for numeric variables. Comparisons of groups of patients with AMI and those with AT were carried out using $X^{2}$ tests and the MannWhitney test (for the relevant category and numerical data). Analyses were conducted using R 3.4.1 software (R Core Team, 2017; Foundation for Statistical Computing, Vienna, Austria; https://www.R-project.org/).

\section{Results}

A total of 48,555 HEMS flights were carried out between 2011 and 2016, out of which 7,645 concerned transport between hospitals in the rescue mode, including 1,429

Table 1. Characteristics of the group of patients with AMI in the study

\begin{tabular}{|c|c|c|c|c|c|}
\hline Variables & $\mathrm{N}$ & $\begin{array}{c}\text { Inter- } \\
\text { Htransport }\end{array}$ & $\mathrm{N}$ & HEMS missions & $p$-value \\
\hline $\begin{array}{l}\text { Sex, n (\%) } \\
\text { F } \\
\text { M } \\
\text { NN }\end{array}$ & 1,438 & $\begin{array}{c}464(32.3) \\
973(67.7) \\
1(0.1)\end{array}$ & 4,002 & $\begin{array}{c}1,239(31.0) \\
2,758(68.9) \\
5(0.1)\end{array}$ & 0.573 \\
\hline Age, median (Q1-Q3) & 1,435 & $65.9(58.0-75.4)$ & 3,975 & $63.6(56.5-73.1)$ & $<0.001$ \\
\hline GCS, median (Q1-Q3) & 953 & $15.0(15.0-15.0)$ & 2,642 & $15.0(15.0-15.0)$ & 0.037 \\
\hline $\begin{array}{l}\text { GCS } \\
\quad<9 \\
9-12 \\
13-14 \\
15\end{array}$ & $\begin{array}{c}27 \\
13 \\
24 \\
1,230\end{array}$ & $\begin{array}{c}2.1 \% \\
1.0 \% \\
1.9 \% \\
95.1 \%\end{array}$ & $\begin{array}{c}105 \\
51 \\
130 \\
3,479\end{array}$ & $\begin{array}{c}2.8 \% \\
1.4 \% \\
3.5 \% \\
92.4 \%\end{array}$ & 0.009 \\
\hline RTS, median (Q1-Q3) & 953 & $12.0(12.0-12.0)$ & 2,639 & $12.0(12.0-12.0)$ & 0.073 \\
\hline
\end{tabular}

AMI - acute myocardial infarction; interHtransport - interhospital transport; HEMS - Helicopter Emergency Medical Service; GCS - Glasgow Coma Scale; RTS - Revised Trauma Score; F - female; $\mathrm{M}$ - male; NN - non notus.

Table 2. Characteristics of the group of trauma patients analyzed in the study

\begin{tabular}{|c|c|c|c|c|c|}
\hline Variables & $\mathrm{N}$ & $\begin{array}{c}\text { Inter- } \\
\text { Htransport }\end{array}$ & $\mathrm{N}$ & HEMS missions & $p$-value \\
\hline $\begin{array}{l}\text { Sex, n (\%) } \\
\text { F } \\
\text { M } \\
\text { NN }\end{array}$ & 916 & $\begin{array}{c}221(24.1) \\
691(75.4) \\
4(0.5)\end{array}$ & 5,231 & $\begin{array}{c}1,361(26.0) \\
3,804(72.7) \\
66(1.3)\end{array}$ & 0.038 \\
\hline Age, median (Q1-Q3) & 895 & $42.1(23.5-57.8)$ & 4,683 & $33.1(19.2-53.5)$ & $<0.001$ \\
\hline GCS, median (Q1-Q3) & 472 & $14.0(3.0-15.0)$ & 3,313 & $14.0(6.0-15.0)$ & 0.007 \\
\hline $\begin{array}{l}\text { GCS } \\
\quad<9 \\
9-12 \\
13-14 \\
15\end{array}$ & $\begin{array}{c}205 \\
58 \\
61 \\
340\end{array}$ & $\begin{array}{c}30.9 \% \\
8.7 \% \\
9.2 \% \\
51.2 \%\end{array}$ & $\begin{array}{c}1,582 \\
459 \\
712 \\
2,286\end{array}$ & $\begin{array}{c}31.4 \% \\
9.1 \% \\
14.1 \% \\
45.4 \%\end{array}$ & 0.002 \\
\hline RTS, median (Q1-Q3) & 471 & $12.0(8.0-12.0)$ & 3,309 & $12.0(9.0-12.0)$ & 0.011 \\
\hline
\end{tabular}

InterHtransport - interhospital transport; HEMS - Helicopter Emergency Medical Service; GCS - Glasgow Coma Scale; RTS - Revised Trauma Score; F - female; M - male; NN - non notus.
AMI patients and 908 AT patients (19\% and 12\% transport flights, respectively). Out of the 40,910 missions directly to the site of the incident, 4,002 were flights to AMI patients and 5,231 to AT patients (10\% and 13\%, respectively).

The basic characteristics of the patients with AMI from each group are presented in Table 1 . In the group of patients with AMI, females transported between hospitals accounted for $32.3 \%$, whereas in the AT group women comprised 31.0\% (not significant (NS)). Male patients comprised $67.7 \%$ and $68.9 \%$ (NS), respectively. Unidentified patients (NN) accounted for $0.1 \%$ of the flights in both groups (NS). The median age of patients transported between hospitals was 65.9 years, and from the scene of the event -63.6 years $(\mathrm{p}<0.001)$.

The median state of consciousness assessed using GCS was 15 points in both groups (NS). The number of GCS points was divided into 4 ranges in patients transported between hospitals was the following: <9: 27 (2.1\%), 9-12: 13 (1.0\%), 13-14: 24 (1.9\%), and 15: 1,230 (95.1\%), while in the HEMS mission it was <9: 105 (2.8\%), 9-12: 51 (1.4\%), 13-14: 130 (3.5\%), and 15: 3,479 (92.4\%). The assessment of patients on the RTS was 12 (NS).

In the group of AT patients, women transported between hospitals accounted for $24.1 \%$, while in the group taken from the place of the event for $26.0 \%$ (NS). The corresponding percentages for men were the following: $75.4 \%$ and $72.7 \%$ (NS), respectively. Unidentified patients accounted for $0.5 \%$ of interhospital flights and $1.3 \%$ of flights from the site of the event (NS). The median age of the patients transported between hospitals was 42.1 years, and from the scene of the event -33.1 years $(\mathrm{p}<0.001)$ (Table 2).

The median state of consciousness on GCS in interHtransport and in flights to the event amounted to 14.0 points (NS). The number of points on GCS divided into 4 ranges for patients transported between hospitals was the following: <9: 205 (30.9\%), 9-12: 58 (8.7\%), 13-14: 61 (9.2\%), and 15: 340 (51.2\%), while the corresponding numbers for the HEMS missions were the following: <9: 1,582 (31.4\%), 9-12: 459 (9.1\%), 13-14: 712 (14.1\%), and 15: 2,286 (45.4\%). The evaluation of patients on the RTS was 12.0 points (NS).

One fatality was registered in each of the groups analyzed (AMI and AT patients). Moreover, cardiac arrest occurred in 9 (0.6\%) patients with AMI in the course of interHtransport, while among patients flown from the scene 
Table 3. Medical rescue procedures carried out by the HEMS (patients with AMI)

\begin{tabular}{|c|c|c|c|c|c|}
\hline Variables & $\mathrm{N}$ & InterHtransport & $\mathrm{N}$ & HEMS missions & $p$-value \\
\hline $\begin{array}{l}\text { Defibrillation, n (\%) } \\
\text { no } \\
\text { yes }\end{array}$ & 1,439 & $\begin{array}{c}1,433(99.6) \\
6(0.4)\end{array}$ & 4,002 & $\begin{array}{c}3,950(98.7) \\
52(1.3)\end{array}$ & 0.008 \\
\hline $\begin{array}{l}\text { CPR, n (\%) } \\
\text { no } \\
\text { yes }\end{array}$ & 1,302 & $\begin{array}{c}1,296(99.5) \\
6(0.5)\end{array}$ & 3,745 & $\begin{array}{c}3,672(98.1) \\
73(1.9)\end{array}$ & $<0.001$ \\
\hline $\begin{array}{l}\text { Intubation, n (\%) } \\
\text { no } \\
\text { yes }\end{array}$ & 1,439 & $\begin{array}{c}1,426(99.1) \\
13(0.9)\end{array}$ & 4,002 & $\begin{array}{c}3,947(98.6) \\
55(1.4)\end{array}$ & 0.215 \\
\hline $\begin{array}{l}\text { Sedation, n (\%) } \\
\text { no } \\
\text { yes }\end{array}$ & 1,439 & $\begin{array}{c}1,343(93.3) \\
96(6.7)\end{array}$ & 4,002 & $\begin{array}{c}3,819(95.4) \\
183(4.6)\end{array}$ & 0.002 \\
\hline $\begin{array}{l}\text { Neuromuscular block, n (\%) } \\
\text { no } \\
\text { yes }\end{array}$ & 1,439 & $\begin{array}{c}1,423(98.9) \\
16(1.1)\end{array}$ & 4,002 & $\begin{array}{c}3,977(99.4) \\
25(0.6)\end{array}$ & 0.098 \\
\hline $\begin{array}{l}\text { Oxygen therapy, n (\%) } \\
\text { no } \\
\text { yes }\end{array}$ & 1,439 & $\begin{array}{c}848(58.9) \\
591(41.1)\end{array}$ & 4,002 & $\begin{array}{l}1,991(49.8) \\
2,011(50.2)\end{array}$ & $<0.001$ \\
\hline $\begin{array}{l}\text { Respirator, n (\%) } \\
\text { no } \\
\text { yes }\end{array}$ & 1,439 & $\begin{array}{c}1,380(95.9) \\
59(4.1)\end{array}$ & 4,002 & $\begin{array}{c}3,900(97.5) \\
102(2.5)\end{array}$ & 0.004 \\
\hline
\end{tabular}

AMI - acute myocardial infarction; HEMS - Helicopter Emergency Medical Service; interHtransport - interhospital transport; CPR - cardiopulmonary resuscitation; GCS - Glasgow Coma Scale; RTS - Revised Trauma Score.

Table 4. Medical rescue procedures carried out by the HEMS (patients with trauma)

\begin{tabular}{|c|c|c|c|c|c|}
\hline Variables & $\mathrm{N}$ & InterHtransport & $\mathrm{N}$ & HEMS missions & $p$-value \\
\hline $\begin{array}{l}\text { Defibrillation, n (\%) } \\
\text { no } \\
\text { yes }\end{array}$ & 916 & $\begin{array}{c}914(99.8) \\
2(0.2)\end{array}$ & 5,231 & $\begin{array}{c}5,208(99.6) \\
23(0.4)\end{array}$ & 0.490 \\
\hline $\begin{array}{l}\text { CPR, n (\%) } \\
\text { no } \\
\text { yes }\end{array}$ & 869 & $\begin{array}{c}864(99.4) \\
5(0.6)\end{array}$ & 5,102 & $\begin{array}{c}4,858(95.2) \\
244(4.8)\end{array}$ & $<0.001$ \\
\hline $\begin{array}{l}\text { Intubation, n (\%) } \\
\text { no } \\
\text { yes }\end{array}$ & 916 & $\begin{array}{c}818(89.3) \\
98(10.7)\end{array}$ & 5,231 & $\begin{array}{c}4,324(82.7) \\
907(17.3)\end{array}$ & $<0.001$ \\
\hline $\begin{array}{l}\text { Sedation, n (\%) } \\
\text { no } \\
\text { yes }\end{array}$ & 916 & $\begin{array}{l}457(49.9) \\
459(50.1)\end{array}$ & 5,231 & $\begin{array}{l}3,958(75.7) \\
1,273(24.3)\end{array}$ & $<0.001$ \\
\hline $\begin{array}{l}\text { Neuromuscular block, n (\%) } \\
\text { no } \\
\text { yes }\end{array}$ & 916 & $\begin{array}{l}788(86.0) \\
128(14.0)\end{array}$ & 5,231 & $\begin{array}{c}4,753(90.9) \\
478(9.1)\end{array}$ & $<0.001$ \\
\hline $\begin{array}{l}\text { Oxygen therapy, n (\%) } \\
\text { no } \\
\text { yes }\end{array}$ & 916 & $\begin{array}{l}755(82.4) \\
161(17.6)\end{array}$ & 5,231 & $\begin{array}{l}3,316(63.4) \\
1,915(36.6)\end{array}$ & $<0.001$ \\
\hline $\begin{array}{l}\text { Respirator, n (\%) } \\
\text { no } \\
\text { yes }\end{array}$ & 916 & $\begin{array}{l}529(57.8) \\
387(42.2)\end{array}$ & 5,231 & $\begin{array}{l}3,631(69.4) \\
1,600(30.6)\end{array}$ & $<0.001$ \\
\hline $\begin{array}{l}\text { Spinal board, n (\%) } \\
\text { no } \\
\text { yes }\end{array}$ & 916 & $\begin{array}{c}759(82.9) \\
157(17.1)\end{array}$ & 5,231 & $\begin{array}{l}1,780(34.0) \\
3,451(66.0)\end{array}$ & $<0.001$ \\
\hline $\begin{array}{l}\text { Cervical collar, n (\%) } \\
\text { no } \\
\text { yes }\end{array}$ & 916 & $\begin{array}{l}770(84.1) \\
146(15.9)\end{array}$ & 5,231 & $\begin{array}{l}1,916(36.6) \\
3,315(63.4)\end{array}$ & $<0.001$ \\
\hline
\end{tabular}

HEMS - Helicopter Emergency Medical Service; interHtransport - interhospital transport;

CPR - cardiopulmonary resuscitation; GCS - Glasgow Coma Scale; RTS - Revised Trauma Score.

A comparison of the medical procedures undertaken during the transport of patients with AMI is presented in Table 3. Clinical events that occurred before and during transport in the interhospital group and in flights from the scene of the event included chest compressions $(\mathrm{n}=6(0.5 \%)$ vs $\mathrm{n}=73(1.9 \%)$, respectively; $\mathrm{p}<0.001)$. As far as defibrillation is concerned, it was carried out in $0.4 \%$ of patients transferred between hospitals and in 1.3\% carried by HEMS missions $(\mathrm{p}=0.008)$.

During the transport of patients in the state of a sudden health risk, medical procedures relevant to each group were implemented. There were 13 instances $(0.9 \%)$ when intubation was carried out in the group of patients transported between hospitals, while in the group transported from the scene there were 55 (1.4\%) such cases (NS). Ninetysix patients $(6.7 \%)$ were given sedation during interHtransport, while in the group of patients transported from the scene there were 183 (4.6\%) such cases (NS). The number of instances when neuromuscular block was used in patients transported between hospital was 16 (1.1\%), while it was administered to $25(0.6 \%)$ patients transported from the scene (NS). Oxygen therapy was carried out in $591(41.1 \%)$ of patients transported between hospitals, while it was performed in 2,011 (50.2\%) patients taken from the scene $(\mathrm{p}<0.001)$. In the same group, respiratory therapy was implemented 102 times (2.5\%), and in the group transported between hospitals -59 times (4.1\%) (NS).

A comparison of the medical procedures undertaken during the transport of patients with AT is presented in Table 4. For AT patients, clinical events that occurred before and during transport in the interhospital group and during flights from the scene of the event included chest compres-

there were $53(1.3 \%)$ such cases. In patients with multiorgan trauma, cardiac arrest was observed in $19(0.3 \%)$ patients transported from the site of the event. sions $(\mathrm{n}=5(0.6 \%)$ vs $\mathrm{n}=244(4.8 \%)$, respectively; $\mathrm{p}<0.001)$ and defibrillation $(0.2 \%$ patients transported between hospitals and $0.4 \%$ transferred by HEMS missions; $\mathrm{p}=0.490$ ). 
Table 5. Analysis of HEMS time and distance (patients with AMI)

\begin{tabular}{|c|c|c|c|c|c|}
\hline Variables & $\mathrm{N}$ & InterHtransport & $\mathrm{N}$ & HEMS missions & p-value \\
\hline Time until reaching the patient, median (Q1-Q3) & 1,412 & $36.0(30.0-44.0)$ & 3,942 & $23.0(19.0-27.0)$ & $<0.001$ \\
\hline $\begin{array}{l}\text { Time from reaching the patient until arrival at the target } \\
\text { medical institution, median (Q1-Q3) }\end{array}$ & 1,423 & $45.0(37.0-54.0)$ & 3,951 & $38.0(32.0-44.0)$ & $<0.001$ \\
\hline Total time of operation, median (Q1-Q3) & 1,401 & $81.0(69.0-95.0)$ & 3,896 & $61.0(54.0-70.0)$ & $<0.001$ \\
\hline Distance of transport, median (Q1-Q3) & 1,433 & $59.4(49.8-42,107.5)$ & 3,910 & $52.1(37.1-42,116.5)$ & $<0.001$ \\
\hline
\end{tabular}

AMI - acute myocardial infarction; HEMS - Helicopter Emergency Medical Service; interHtransport - interhospital transport.

Table 6. Analysis of HEMS time and distance (patients with trauma)

\begin{tabular}{|c|c|c|c|c|c|}
\hline Variables & $\mathrm{N}$ & InterHtransport & $\mathrm{N}$ & HEMS missions & $p$-value \\
\hline Time until reaching the patient, median (Q1-Q3) & 889 & $46.0(35.0-58.0)$ & 5,136 & $23.0(19.0-29.0)$ & $<0.001$ \\
\hline $\begin{array}{l}\text { Time from reaching the patient until arrival at the target } \\
\text { medical institution, median }(\mathrm{Q} 1-\mathrm{Q} 3)\end{array}$ & 895 & $66.0(50.0-85.0)$ & 5,043 & $45.0(37.0-55.0)$ & $<0.001$ \\
\hline Total time of operation, median (Q1-Q3) & 875 & $115.0(90.0-141.0)$ & 4,962 & $70.0(58.0-83.0)$ & $<0.001$ \\
\hline Distance of transport, median (Q1-Q3) & 911 & $135.9(66.6-42,141.1)$ & 4,920 & $56.3(34.0-42,181.3)$ & $<0.001$ \\
\hline
\end{tabular}

HEMS - Helicopter Emergency Medical Service; interHtransport - interhospital transport.

Table 7. Number and percentage of missions carried out to the TC as part of transport between hospitals and directly from the scene of the event

\begin{tabular}{|c|c|c|c|c|c|c|c|c|}
\hline \multirow{4}{*}{ Variable } & \multicolumn{4}{|c|}{ InterHtransport } & \multicolumn{4}{|c|}{ HEMS missions } \\
\hline & \multicolumn{8}{|c|}{ TCs in Poland - 14} \\
\hline & \multicolumn{2}{|c|}{ no } & \multicolumn{2}{|c|}{ yes } & \multicolumn{2}{|c|}{ no } & \multicolumn{2}{|c|}{ yes } \\
\hline & $\mathrm{N}$ & {$[\%]$} & $\mathrm{N}$ & [\%] & $\mathrm{N}$ & {$[\%]$} & $\mathrm{N}$ & {$[\%]$} \\
\hline T06 & 19 & 21.1 & 71 & 78.9 & 234 & 13.9 & 1,454 & 86.1 \\
\hline
\end{tabular}

TC - trauma center; HEMS - Helicopter Emergency Medical Service; interHtransport - interhospital transport.

Intubation in the group of patients transported between hospitals was performed 98 times $(10.7 \%)$ and in the group transported from the place of the incident - 907 times $(17.3 \%)(p<0.001)$. The number of times sedation was applied in the case of interHtransport was 459 (50.1\%), while in the group of patients transported from the scene it was $1,273(24.3 \%)$ ( $\mathrm{p}<0.001)$. The number of times neuromuscular block was used in patients transported between hospitals was 128 (14.0\%), and 478 (9.1\%) in patients taken from the scene $(\mathrm{p}<0.001)$. Oxygen therapy and respiratory therapy were applied 161 times (17.6\%) and 387 times (42.2\%) in patients transported between hospitals, and 1,915 times (36.6\%) and 1,600 times (30.6\%) in patients taken from the scene of the incident, respectively ( $\mathrm{p}<0.001)$. Spinal board was used in $3,451(66.0 \%)$ patients transported from the incident site, and in 157 (17.1\%) patients transported between hospitals ( $\mathrm{p}<0.001)$. The cervical collar was placed in 3,315 $(63.4 \%)$ and 146 (15.9\%) cases, respectively ( $<<0.001)$.

Information on the technical parameters of the flight - time till reaching and transporting the patient as well as the total time and distance of the mission - are presented in Tables 5 and 6. Median time from take-off until reaching the patient with AMI in the case of interHtransport was $36 \mathrm{~min}$. In the case of HEMS missions, it was $23 \mathrm{~min}(\mathrm{p}<0.001)$. The time from taking the patient from hospital until arrival at the target medical institution and then transferring the patient to the reference center was $45 \mathrm{~min}$. In the case of HEMS missions, this was $38 \min (\mathrm{p}<0.001)$. The total time of the operation was $81 \mathrm{~min}$ vs $61 \mathrm{~min}$ for interHtransport and the HEMS missions, respectively $(\mathrm{p}<0.001)$. The median distance for interHtransport was $59.4 \mathrm{~km}$, and $52.1 \mathrm{~km}$ (p < 0.001) for flights from the scene of the incident.

Median time from take-off until reaching the patient with AT in the case of interHtransport was $46 \mathrm{~min}$ and for the HEMS missions it was 23 min ( $<<0.001)$. The time from reaching the patient until arrival at the target medical institution and then taking the patient to the reference center was 66 min for transport between hospitals, while in the case of HEMS missions it was $45 \min (\mathrm{p}<0.001)$. The total time of interHtransport operations was $115 \mathrm{~min}$ and in the case of a HEMS mission it was $70 \mathrm{~min}(\mathrm{p}<0.001)$. The median distance of transport for interHtransport was $135.9 \mathrm{~km}$, and for flights from the scene it was $56.3 \mathrm{~km}$ ( $\mathrm{p}<0.001)$ (Table 7).

Patients diagnosed with T06 were most frequently transported to TCs both from the scene of the incident (86.1\%) as well as by interHtransport (78.9\%). The median distance of transport of an AMI patient (I 20, I21 and I24) across Poland (all bases) is between $41.2 \mathrm{~km}$ and $49.8 \mathrm{~km}$. It is noteworthy that $95 \%$ of HEMS missions are shorter than $68.8-86.0 \mathrm{~km}$ for relevant bases (Fig. 1). 


\section{Discussion}

The present publication is the first one in Poland to assess the course and results of HEMS interHtransport and flights to the immediate scene of the emergency incident regarding AMI or AT patients.

In the years 2011-2016 a total of 7,645 transport operations were carried out between medical entities and 4,002 missions took place directly from the scene of the incident. Out of these, patients with AMI and AT constituted a vast majority. Similarly to the data published in other countries, men comprised a decisive majority of the AMI patients in both groups $(67.7 \%$ were transported between hospitals and $68.9 \%$ from the scene of the event). Trauma patients were younger than AMI ones - aged 42.1 years for those transported between hospitals and 33.1 years from the scene, vs 65.9 and 63.6 years of age for AMI patients. ${ }^{13}$

The most frequent level of consciousness on GCS was on average 15 points (based on data on 953 patients transported between hospitals and 2,642 taken from the scene - there was a lack of data on the others). There were 27 patients with GCS below 9 points, which constituted $2.1 \%$. In the range between 9 and 12 points, the number of patients was 13 (1.0\%); 24 patients scored $13-14$ points (1.9\%), while 1,230 were given 15 points (95.1\%). In the HEMS missions, the corresponding numbers were the following: <9: 105 (2.8\%), 9-12: 51 (1.4\%), 13-14: 130 (3.5\%), and $15: 3,479$ (92.4\%). This means that the patients were in logical and verbal contact and there were no disorders of consciousness in both groups of AMI patients. In the case of AT patients, the GCS consciousness level was on average 14 points (on the basis of data regarding 472 and 3,313 patients, respectively - there was a lack of data on the others). The number of points on the GCS varied widely. There were 205 patients with GCS below 9 points, which constituted $30.9 \%$. In the range between 9-12 points, the number of patients was 58 (8.7\%); 61 patients scored 13-14 points (9.2\%), while 340 were given 15 points (51.2\%). In the HEMS missions, the corresponding numbers were the following: <9: 1,582 (31.4\%), 9-12: 459 (9.1\%), 13-14: 712 (14.1\%), and 15: 2,286 (45.4\%). Such results lead to the conclusion that a significant percentage of patients were unconscious or had moderately disturbed consciousness. While the assessment of patients on the RTS scale on average amounted to 12 , this was also true in both groups of AT patients. Similarly to reports in the literature, the scales show that the status of the AT patients was significantly more severe in comparison to AMI patients. ${ }^{10}$ In another publication, the level of consciousness in patients with AMI was assessed at 13 points, while of those with AT at 11.9. ${ }^{13}$ In some cases, the implementation of additional medical procedures for the time of transport was necessary (sedation, intubation, respiratory therapy).

The clinical procedures undertaken due to the state of the AMI patients included the following: chest compression $(n=6 ; n=73)$ and defibrillation $0.4 \%$ and $1.3 \%$,

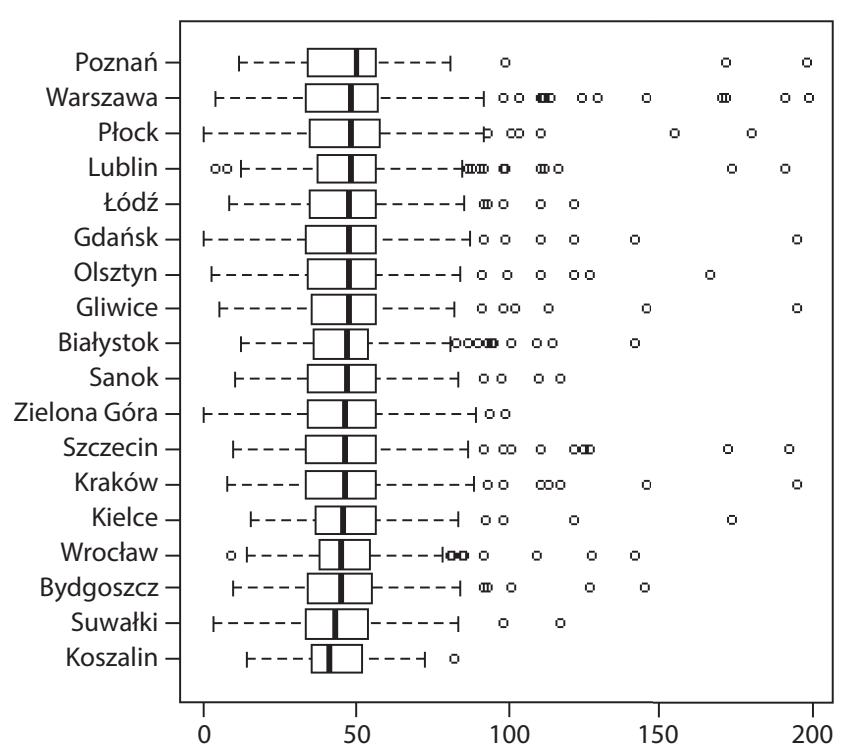

Fig. 1. Analysis of the distance of transport of patients with AMI to the departments of hemodynamics in Poland

while for patients with AT clinical procedures involved defibrillation $0.2 \%$ and $0.4 \%$; and chest compressions $(n=5$; $\mathrm{n}=244)$. The disorders described occurred both before and in the course of the helicopter flight. The European Society of Cardiology guidelines recommends that patients transported between hospitals should be accompanied by personnel adequately equipped and trained to deal with life-threatening arrhythmias and cardiac arrest. ${ }^{14-16}$ There were no fatalities in the course of the flights between hospitals. Nevertheless, there was a fatality incident which one team experienced when flying an AMI patient from the scene of the incident. Analysis showed that the occurrence of cardiac arrest (146) was more frequent in patients with AMI (I21) than in those with multi-organ trauma (T06). On the basis of the data they received, the authors are unable to determine the moment of cardiac arrest.

In McMullan's study, it was reported that in the course of interHtransport, cardiopulmonary resuscitation was necessary only in 2 patients. ${ }^{4}$ This may result from the proper preparation of patients before transport and accurate enrollment of patients who can benefit from aeromedical transport. Analysis showed that oxygen therapy was implemented in 591 and in 2,011 patients with AMI in interHtransport and transport from the scene of the incident, respectively, while sedation in was carried out in 96 and 183 patients, respectively, and respiratory therapy was necessary in 59 and 102 patients, respectively. In AT patients, on the other hand, the most frequently used therapy was sedation ( $\mathrm{n}=459 ; \mathrm{n}=1,273)$ and respiratory therapy $(\mathrm{n}=387 ; \mathrm{n}=1,600)$ due to severe body injuries and the risk of secondary cardiopulmonary disorders. In this group, oxygen therapy $(\mathrm{n}=161 ; \mathrm{n}=1,915)$, neuromuscular block $(\mathrm{n}=128 ; \mathrm{n}=478)$ and intubation $(\mathrm{n}=98 ; \mathrm{n}=907)$ were also frequent. The percentage of intubation in the American study was different than in ours: patients with AMI 
and AT who received intubation comprised $24 \%$ and $22 \%$ of those transported between hospitals and from the scene of the incident, respectively, which constitutes a significant difference with respect to the data reported in the present study (AMI $0.9 \%$ and $1.4 \%$, AT $10.7 \%$ and $17.3 \%$, respectively).$^{12}$ In the first case (AMI patients), the difference can result from the fact that Polish patients received intensive care protecting them prior to transport by the dispatching entities and were subsequently looked after by MARS teams. The group of patients with AT demanded more careful preparation for the flight, what was analyzed on the basis of the number of undertaken medical rescue procedures, It reflects their more severe condition.

The median of the distance of flight from the dispatching center to the target in the case of AMI or AT was $59.4 \mathrm{~km}$ (AMI - interHtransport) and $52.1 \mathrm{~km}$ (AMI - HEMS mission) vs $135.9 \mathrm{~km}$ (AT - interHtransport) and $56.3 \mathrm{~km}$ (AT - HEMS mission), respectively, while the median of the transport time was 45 min (AMI - interHtransport) and 38 min (AMI - HEMS mission), and 66 min (AT - interHtransport) and 45 min (AT - HEMS mission), respectively. The data from the literature differs: the average flight distance with AMI is $70 \mathrm{~km}$ and flight time - $31 \mathrm{~min}$, while in the case of AT patients the flight time is $121 \mathrm{~min}$, while there is a lack of data for flight distance. ${ }^{10,17}$ The reason for the differences observed is most likely due to the following factors: the density of HEMS bases and target centers, the kind of helicopters, and the organization of the land medical care that takes the patient to HEMS. Moreover, procedural differences between HEMS teams in different countries should not be excluded.

Trauma to multiple areas of the body or multi-organ injuries should ultimately be treated with therapy in TC. Therefore, at the stage of receiving the call for help, it is advisable to immediately dispatch HEMS to patients with multi-organ trauma to avoid unnecessary delay of proper treatment in a TC.

The paper presents a comparison of transport of AT patients to the hospital where there is a TC. Among AT patients, the criteria for treatment in a $\mathrm{TC}$ were met by patients diagnosed with T06 - injuries involving numerous body regions according to the ICD-10 codes. Patients with multiple-organ trauma most often came directly from the accident site.

Another analysis of HEMS missions between the years 2011-2013 in Poland also showed that the AT patients most often transported to a TC were those classified into the T06 group. ${ }^{18}$

The study also included an analysis of the distance over which patients with AMI were transported to hemodynamic departments. It was shown that in Poland there are no significant differences between the distances of transporting patients with AMI, which makes it possible to conclude that the location of hemodynamic centers in Poland is optimal.

According to the author's analysis, patients with AMI before the arrival of HEMS received pain relief from the personnel of ambulances - it was probably administered after the examination of the patient. Analgesic drugs were also provided by the hospitals to which the patients were sent. The most commonly administered drug in both groups of transport was morphini sulfas. Air teams more often than ground teams administered fentanylum, which may result from their greater experience with pain relief therapy.

In AT patients, both ambulances and hospitals administered morphini sulfas, fentanylum and ketoprofenum. The HEMS units used fentanylum and morphini sulfas in fractionated doses. Drugs from other groups were administered occasionally (detailed tables are shown in the supplementary data).

Krzyżanowski et al. in a Polish study carried out in the Pomeranian voivodeship indicated that in ground emergency medical teams, only $16 \%$ of AT patients are treated with analgesics. The most frequent drug is ketoprofenum. It was shown that $84 \%$ of all patients were transported to the hospital without painkillers. ${ }^{19}$ The study became the reason for the Ministry of Health to implement guidelines for ground and air emergency medical teams in the area of proper pain management.

\section{Limitations of the study}

The main limitation of the study is its retrospective character and the lack of possibility to follow-up the further fate of the patients. Nevertheless, an analysis was done of all the patients transported by HEMS in the timeframe reported, thus minimizing the risk that a systematic error of the selection should occur.

\section{Conclusions}

In Poland, HEMS is more readily available and more frequently administered for transport from the place of the event than for interhospital transfer. The interhospital air transport of AMI patients compared to transport from the emergency scene requires less advanced life-saving procedures with the exception of neuromuscular block, sedation and respiratory therapy. Similarities in these areas are also observed in the group of patients with AT. Longer distances or longer transport times of AT patients reflect the existence of fewer TCs compared to hemodynamic TCs. The location of hemodynamic centers in Poland, according to the results of the study, is optimal.

Patients diagnosed with T06 carried both by interHtransport and from the scene of the incident are most often transferred to TCs. 


\section{ORCID iDs}

Arkadiusz Wejnarski (10 https://orcid.org/0000-0003-1454-6664 Piotr Leszczyński @i] https://orcid.org/0000-0002-3408-3591 Stanisław Świeżewski (10 https://orcid.org/0000-0001-9665-2182 Marcin Podgórski (1) https://orcid.org/0000-0003-1373-4057 Michał M. Farkowski (1) https://orcid.org/0000-0003-1673-7712 Maciej Sterliński (10) https://orcid.org/0000-0001-5250-3679 Mariusz Panczyk (1) https://orcid.org/0000-0003-1830-2114 Joanna Gotlib (1) https://orcid.org/0000-0002-2717-7741 Daniel Rabczenko (1) https://orcid.org/0000-0002-9746-2003 Robert Gałązkowski (1) https://orcid.org/0000-0002-7205-2219

\section{References}

1. Phillips $M$, Arthur AO, Chandwaney R, et al. Helicopter transport effectiveness of patients for primary percutaneous coronary intervention. Air Med J. 2013;32(3):144-152. doi:10.1016/j.amj.2012.08.007

2. Blankenship JC, Haldis TA, Wood GC. Rapid triage and transport of patients with ST-elevation myocardial infarction for percutaneous coronary intervention in a rural health system. Am J Cardiol. 2007; 100(6):944-948.

3. Levine GN, Bates ER, Blankenship JC, et al. 2011 ACCF/AHA/SCAI Guideline for Percutaneous Coronary Intervention: A report of the American College of Cardiology Foundation/American Heart Association Task Force on Practice Guidelines and the Society for Cardiovascular Angiography and Interventions. Circulation. 2011;124:e574-e651.

4. McMullan JT, Hinckley W, Bentley J, et al. Ground emergency medical services requests for helicopter transfer of ST-segment elevation myocardial infarction patients decrease medical contact to balloon times in rural and suburban settings. Acad Emerg Med. 2012;19(2): 153-160. doi:10.1111/j.1553-2712.2011.01273.x

5. Wilson BH, Humphrey AD, Cedarholm JC, et al. Achieving sustainable first door-to-balloon times of 90 minutes for regional transfer ST-segment elevation myocardial infarction. JACC Cardiovasc Interv. 2013;6(10):1064-1071. doi:10.1016/j.jcin.2013.05.018

6. Warren J, Fromm RE Jr, Orr RA, et al. Guidelines for the inter- and intrahospital transport of critically ill patients. Crit Care Med. 2004;32(1): 256-262.

7. Wejnarski A, Podgórski M, Kamecki A, Świeżewski S. The role of the Polish Medical Air Rescue in optimization of transport time of patients with burns. Anest Ratow. 2016;10:269-280.
8. Gałązkowski R, Świeżewski SP, Rabczenko D, et al. Rescue procedures in the major trauma of upper extremities - the role of the Polish medical air rescue in the therapeutic process. Med Pr. 2014;65(6):765-776.

9. Mann NC, Pinkney KA, Price DD, et al. Injury mortality following the loss of air medical support for rural interhospital transport. Acad Emerg Med. 2002;9(7):694-698.

10. Borst GM, Davies SW, Waibel BH. When birds can't fly: An analysis of interfacility ground transport using advanced life support when helicopter emergency medical service is unavailable. J Trauma Acute Care Surg. 2014;77(2):331-336, discussion 336-337. doi:10.1097/TA. 0000000000000295

11. Thomas SH, Harrison TH, Buras WR, et al. Helicopter transport and blunt trauma mortality: A multicenter trial. JTrauma. 2002;52:136-145.

12. Grines $C L$, Westerhausen DR Jr. A randomized trial of transfer for primary angioplasty versus on-site thrombolysis in patients with highrisk myocardial infarction: The Air Primary Angioplasty in Myocardial Infarction study. J Am Coll Cardiol. 2002;39(11):1713-1719.

13. Leira EC, Lamb DL, Nugent AS. Feasibility of acute clinical trials during aerial interhospital transfer. Stroke. 2006;37(10):2504-2507.

14. Roffi M, Patrono C, Collet JP, et al. 2015 ESC guidelines for the management of acute coronary syndromes in patients presenting without persistent ST-segment elevation. Kardiol Pol. 2015;73(12):1207-1294. doi:10.5603/KP.2015.0243

15. Boczkowska K, Bakalarski P, Sviatoslav M, Leszczyński PK. The importance of e-learning in professional improvement of emergency nurses. Critic Care Innov. 2018;1(1):16-24.

16. Wejnarski A, Gajek Villebæk PA, Leszczyński PK. Prospective evaluation of interactive project of Emergency Medicine Exam with the use of multimedia computer devices. Critic Care Innov. 2018;1(1):1-15.

17. Nicholson BD, Dhindsa HS, Roe MT. Relationship of the distance between non- $\mathrm{PCl}$ hospitals and primary $\mathrm{PCl}$ centers, mode of transport, and reperfusion time among ground and air interhospital transfers using NCDR's ACTION Registry-GWTG. A Report from the American Heart Association Mission: Lifeline Program. Circ Cardiovasc Interv. 2014;7(6):797-805. doi:10.1161/CIRCINTERVENTIONS.113.001307

18. Gałązkowski R, Guła P, Karwan K, Rabczenko D, Żyła Z. Analysis of the work done by the Warsaw and Płock Helicopter Emergency Medical Service (HEMS) teams regarding help given to patients with serious bodily injuries transported to the Trauma Centre in Warsaw between the years 2011-2013. Lek Wojsk. 2014;92(3):255-262.

19. Krzyżanowski K, Ślęzak D, Basiński A, Żuratyński P, Buca P. Relieving pain on prehospital stage: Preliminary study. Pain. 2017:18(1):37-43. 


\section{Appendix - supplementary data}

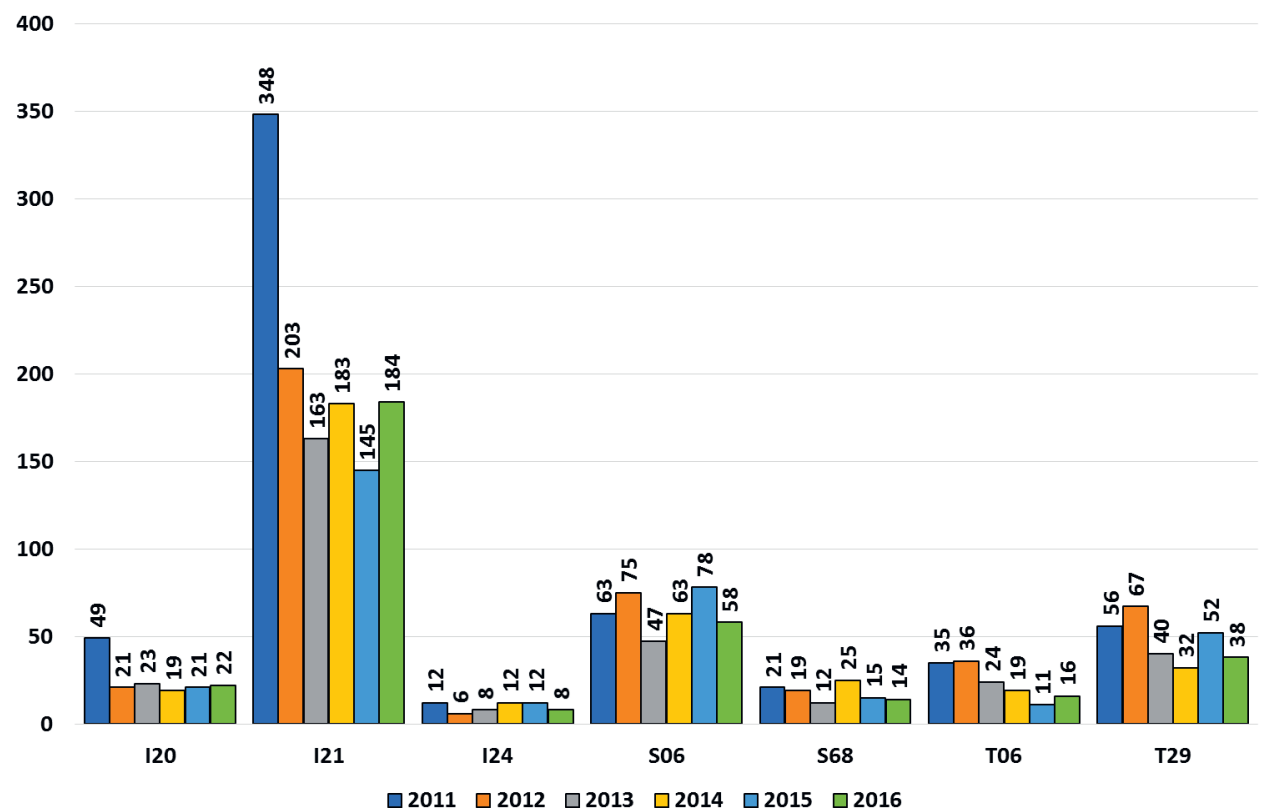

Fig. 2. The number of times interhospital aeromedical transport was used for patients with AMI and selected AT patients during the period analyzed

In the present analysis, the largest number of cases transported to interventional cardiology departments in order to implement the PCl procedure were those with the I 21 diagnosis (AMI). It is noticeable that over this timespan there is a decreasing tendency in the number of patients with AMI transported by air. The authors assume that in subsequent years interventional cardiology units were established in or near the hospitals ordering the air dispatch of such patients, which reduced the need for air transport. On the other hand, the number of times air transport that was used for AT patients remained on a similar level, probably due to the constant number of TCs. Since there are only over a dozen such centers operating in Poland now and a few replantation and burn centers, the transport of AT patients takes longer than that of AMI patients.

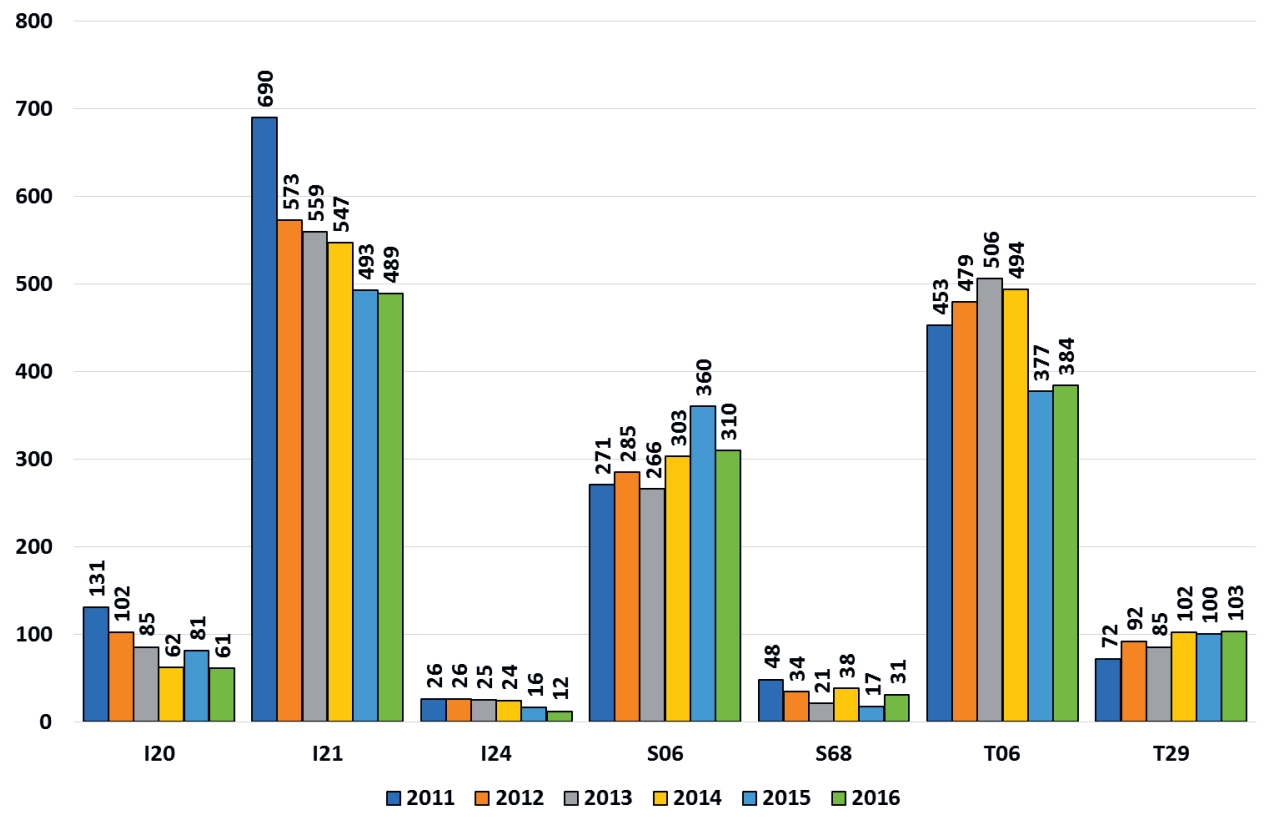

Fig. 3. The number of HEMS missions of patients with AMl and selected acute trauma patients by year

Among the patients transported directly from the scene of the incident, those diagnosed with 121, S06 and T06 were transferred mainly to interventional cardiology departments, replantation centers and TCs, respectively. 
Table 8. The frequency of using selected medication by MARS teams in the course of interHtransport and HEMS missions in patients with AMI and AT

\begin{tabular}{|c|c|c|c|c|c|c|c|c|}
\hline \multirow[b]{3}{*}{ Total number of patients } & \multicolumn{4}{|c|}{ AT } & \multicolumn{4}{|c|}{ AMI } \\
\hline & \multicolumn{2}{|c|}{ HEMS missions } & \multicolumn{2}{|c|}{ interHtransport } & \multicolumn{2}{|c|}{ HEMS missions } & \multicolumn{2}{|c|}{ interHtransport } \\
\hline & 5,231 & $100 \%$ & 916 & $100 \%$ & 4,002 & $100 \%$ & 1,439 & $100 \%$ \\
\hline Sodium chlorine & 3,310 & $63.3 \%$ & 368 & $40.2 \%$ & 970 & $24.2 \%$ & 180 & $12.5 \%$ \\
\hline Acidum acetylsalicylicum & 7 & $0.1 \%$ & 2 & $0.2 \%$ & 2,967 & $74.1 \%$ & 747 & $51.9 \%$ \\
\hline Clexane & 0 & $0.0 \%$ & 7 & $0.8 \%$ & 101 & $2.5 \%$ & 194 & $13.5 \%$ \\
\hline Clopidogrelum & 4 & $0.1 \%$ & 1 & $0.1 \%$ & 696 & $17.4 \%$ & 80 & $5.6 \%$ \\
\hline Heparinum sulfas & 6 & $0.1 \%$ & 4 & $0.4 \%$ & 1,571 & $39.3 \%$ & 474 & $32.9 \%$ \\
\hline Morphini sulfas & 1,437 & $27.5 \%$ & 237 & $25.9 \%$ & 2,668 & $66.7 \%$ & 435 & $30.2 \%$ \\
\hline Nitroglicerin & 2 & $0.0 \%$ & 1 & $0.1 \%$ & 653 & $16.3 \%$ & 154 & $10.7 \%$ \\
\hline Ondasteronum & 394 & $7.5 \%$ & 36 & $3.9 \%$ & 482 & $12.0 \%$ & 119 & $8.3 \%$ \\
\hline Midazolamum & 1,447 & $27.7 \%$ & 309 & $33.7 \%$ & 207 & $5.2 \%$ & 135 & $9.4 \%$ \\
\hline Rocuronium & 573 & $11.0 \%$ & 62 & $6.8 \%$ & 26 & $0.6 \%$ & 4 & $0.3 \%$ \\
\hline Propofol & 783 & $15.0 \%$ & 91 & $9.9 \%$ & 21 & $0.5 \%$ & 5 & $0.3 \%$ \\
\hline Ticagrelor & 0 & $0.0 \%$ & 0 & $0.0 \%$ & 1 & $0.0 \%$ & 0 & $0.0 \%$ \\
\hline Ketoprofenum & 603 & $11.5 \%$ & 51 & $5.6 \%$ & 49 & $1.2 \%$ & 18 & $1.3 \%$ \\
\hline Metamizolum & 97 & $1.9 \%$ & 28 & $3.1 \%$ & 31 & $0.8 \%$ & 8 & $0.6 \%$ \\
\hline Tramadol & 34 & $0.6 \%$ & 16 & $1.7 \%$ & 2 & $0.0 \%$ & 0 & $0.0 \%$ \\
\hline Ketamine & 164 & $3.1 \%$ & 18 & $2.0 \%$ & 1 & $0.0 \%$ & 1 & $0.1 \%$ \\
\hline Paracetamolum & 44 & $0.8 \%$ & 8 & $0.9 \%$ & 2 & $0.0 \%$ & 0 & $0.0 \%$ \\
\hline Fentanylum & 2,727 & $52.1 \%$ & 297 & $32.4 \%$ & 159 & $4.0 \%$ & 25 & $1.7 \%$ \\
\hline Plavix & 4 & $0.1 \%$ & 2 & $0.2 \%$ & 1,819 & $45.5 \%$ & 666 & $46.3 \%$ \\
\hline Compound electrolyte so & 1,134 & $21.7 \%$ & 194 & $21.2 \%$ & 273 & $6.8 \%$ & 65 & $4.5 \%$ \\
\hline Wekuronuim & 314 & $6.0 \%$ & 41 & $4.5 \%$ & 7 & $0.2 \%$ & 5 & $0.3 \%$ \\
\hline Atropinum & 318 & $6.1 \%$ & 19 & $2.1 \%$ & 179 & $4.5 \%$ & 7 & $0.5 \%$ \\
\hline Epinephryne & 306 & $5.8 \%$ & 8 & $0.9 \%$ & 114 & $2.8 \%$ & 13 & $0.9 \%$ \\
\hline Thiopental & 309 & $5.9 \%$ & 55 & $6.0 \%$ & 8 & $0.2 \%$ & 2 & $0.1 \%$ \\
\hline
\end{tabular}

MARS - Medical Air Rescue Service; HEMS - Helicopter Emergency Medical Service; AMI - acute myocardial infarction; AT - acute trauma; interHtransport - interhospital transport.

Table 9. The frequency of using analgesic medication by MARS teams in the course of interHtransport and HEMS missions to help patients with AMI

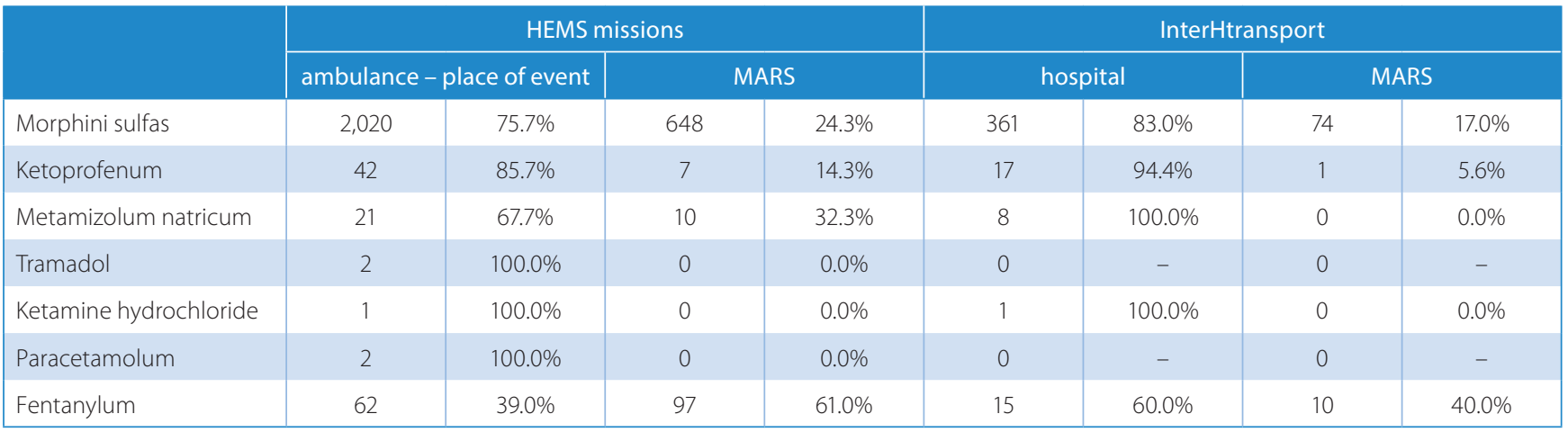

MARS - Medical Air Rescue Service; HEMS - Helicopter Emergency Medical Service; AMI - acute myocardial infarction; interHtransport - interhospital transport. 
Table 10. The frequency of using analgesic medication by MARS teams in the course of interHtransport and HEMS missions to help patients with AT

\begin{tabular}{|c|c|c|c|c|c|c|c|c|}
\hline \multirow{3}{*}{$\begin{array}{l}\text { Analgesic administered } \\
\text { Morphini sulfas }\end{array}$} & \multicolumn{4}{|c|}{ InterHtransport } & \multicolumn{4}{|c|}{ HEMS mission } \\
\hline & \multicolumn{2}{|c|}{ ambulance - place of event } & \multicolumn{2}{|c|}{ MARS } & \multicolumn{2}{|c|}{ hospital } & \multicolumn{2}{|c|}{ MARS } \\
\hline & 1,058 & $73.6 \%$ & 379 & $26.4 \%$ & 167 & $70.5 \%$ & 70 & $29.5 \%$ \\
\hline Ketoprofenum & 469 & $77.8 \%$ & 134 & $22.2 \%$ & 45 & $88.2 \%$ & 6 & $11.8 \%$ \\
\hline Metamizolum natricum & 73 & $75.3 \%$ & 24 & $24.7 \%$ & 24 & $85.7 \%$ & 4 & $14.3 \%$ \\
\hline Tramadol & 34 & $100.0 \%$ & 0 & $0.0 \%$ & 16 & $100.0 \%$ & 0 & $0.0 \%$ \\
\hline Ketamine hydrochloride & 20 & $12.2 \%$ & 144 & $87.8 \%$ & 12 & $66.7 \%$ & 6 & $33.3 \%$ \\
\hline Paracetamolum & 44 & $100.0 \%$ & 0 & $0.0 \%$ & 8 & $100.0 \%$ & 0 & $0.0 \%$ \\
\hline Fentanylum & 729 & $26.7 \%$ & 1,998 & $73.3 \%$ & 145 & $48.8 \%$ & 152 & $51.2 \%$ \\
\hline
\end{tabular}

MARS - Medical Air Rescue Service; HEMS - Helicopter Emergency Medical Service; AT - acute trauma; interHtransport - interhospital transport.

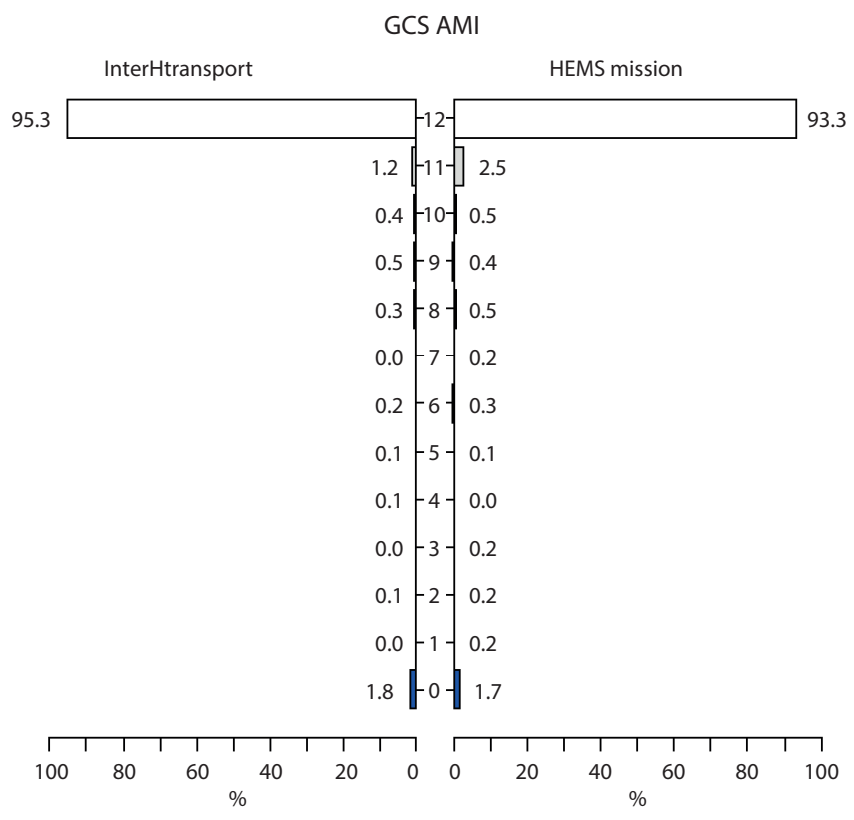

RTS MI

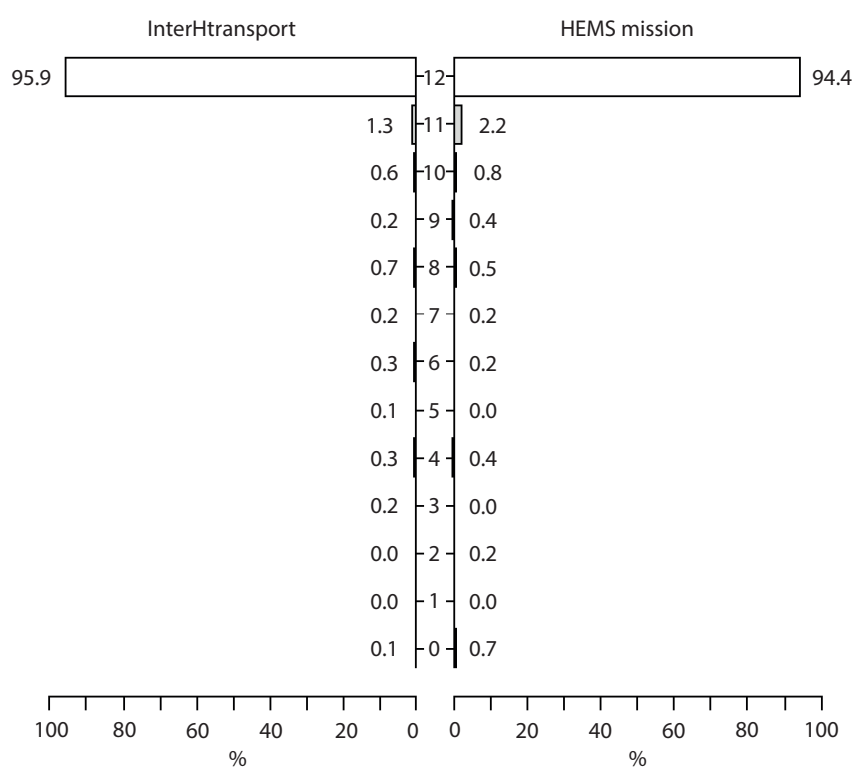

GCS trauma
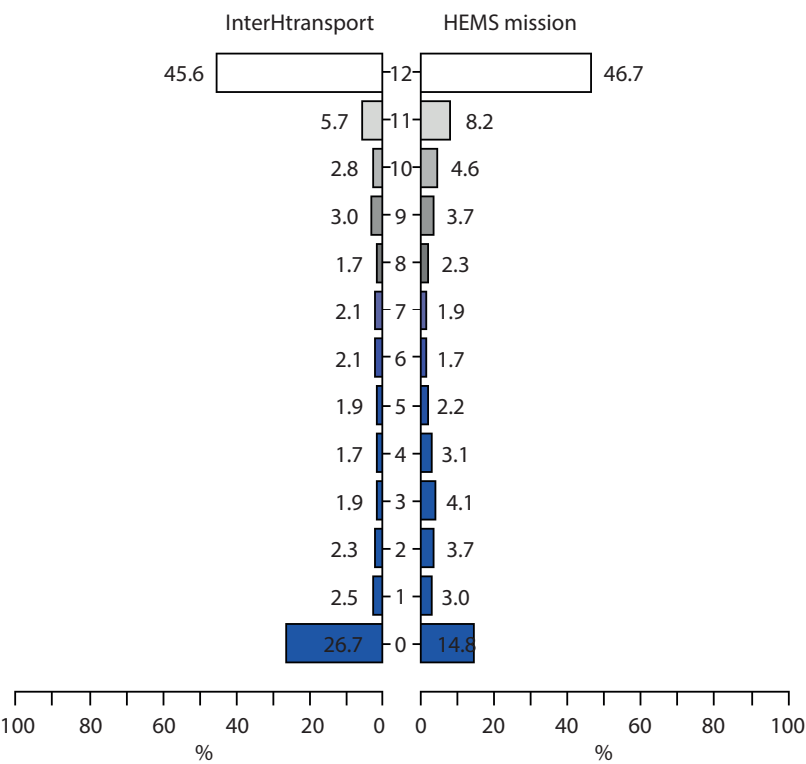

RTS trauma
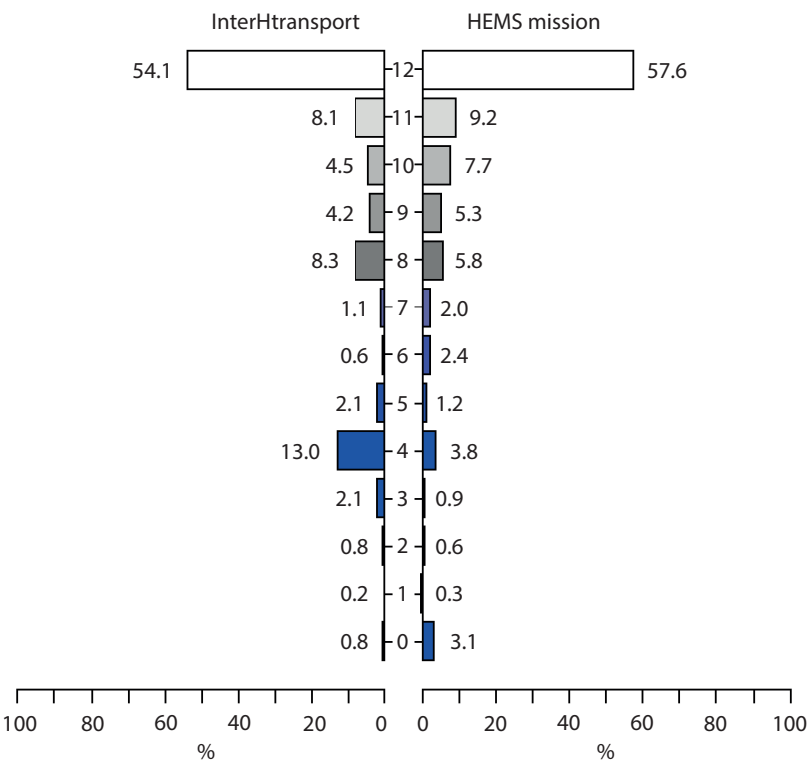

Fig. 4. RTS and GCS scale distribution in the group of patients with AMI and AT 